\title{
LA LUCHA CONTRA EL TRÁFICO DE ESPECIES SILVESTRES EN AMÉRICA DEL SUR
}

Vania Tuglio*

"La delincuencia silvestre y forestal exige una solución global que ofrezca cooperación internacional basada en operaciones conjuntas, intercambio de inteligencia y legislaciones nacionales fuertes y compatibles. No podemos hacer nada menos. Este es nuestro planeta compartido; la vida silvestre y la delincuencia forestal es nuestra responsabilidad compartida". ${ }^{1}$

De hecho, el tráfico es una práctica criminal presente en todo el mundo, desafía los organismos gubernamentales y, a veces, puede desestabilizar a los Estados, no solamente por los el perjuicio del crimen, sino también por la criminalidad conexa. También impacta negativamente a las especies amenazadas, a los medios de subsistencia de las personas y al desarrollo social y económico. El comercio ilegal del crimen organizado, según los datos del UNDOC mueve alrededor de US\$1.6 trillones a 2.2 trillones anuales, según el cuadro abajo: ${ }^{2}$

\section{The Retail Value of Transnational Crime} Drug Trafficking Small Arms \& Light Weapons Trafficking $\$ 1.7$ billion to $\$ 3.5$ billion Human Trafficking Organ Trafficking Trafficking in Cultural Property Counterfeiting Illegal Wildlife Trade

IUU Fishing Illegal Logging Illegal Mining Crude Oil Theft Total
Estimated Annual Value (US\$) $\$ 426$ billion to $\$ 652$ billion

$\$ 150.2$ billion $\$ 840$ million to $\$ 1.7$ billion $\$ 1.2$ billion to $\$ 1.6$ billion $\$ 923$ billion to $\$ 1.13$ trillion $\$ 5$ billion to $\$ 23$ billion $\$ 15.5$ billion to $\$ 36.4$ billion $\$ 52$ billion to $\$ 157$ billion $\$ 12$ billion to $\$ 48$ billion $\$ 5.2$ billion to $\$ 11.9$ billion $\$ 1.6$ trillion to $\$ 2.2$ trillion

"Los miles de millones de dólares generados por este negocio ilegal se están utilizando para otros fines nefastos. En algunos casos el dinero va a financiar el terrorismo y contribuir a la inestabilidad. Estos crímenes también están estrechamente vinculados con el blanqueo de dinero, la corrupción, el asesinato y la violencia extrema". ${ }^{3}$

\footnotetext{
1 Yury Fedotov en el "Wildlife and Forest Crime - Un crimen organizado transnacional" 22 a CCPCJ, abril de 2013 (https://www.unodc.org/unodc/en/wildlife-and-forest-crime/index.html ) - 1-4-2017-14h11m.

${ }^{2}$ http://www.gfintegrity.org/report/transnational-crime-and-the-developing-world/-1-4-2017 - 18h26m.

${ }^{3}$ https://www.unodc.org/unodc/en/wildlife-and-forest-crime/overview.html - 1-4-2017 - 15h18m.
} 


\author{
Cuando hablamos de tráfico ilícito de fauna, queremos decir la \\ explotación de
}

la fauna y de la flora del mundo. La captura, muerte, comercio, importación, exportación, posesión, uso y obtención de fauna silvestre nativa o en ruta migratoria, viva o muerta, y sus partes o productos. Pero también se refiere a productos forestales, madereros o no.

En la actualidad, los casos más conocidos en la prensa son las muertes de 3 especímenes en riesgo de extinción - los elefantes, los rinocerontes y los tigres -, para sacarles el marfil, los cuernos y la piel. ${ }^{4}$
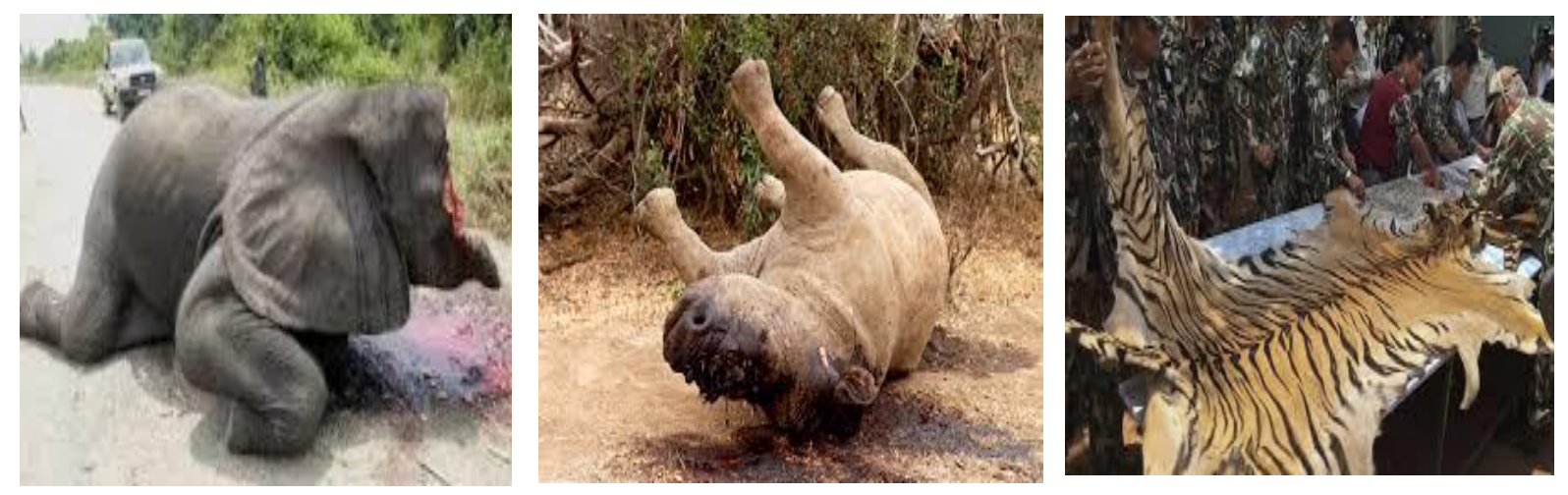

A parte de la crueldad de estas conductas, hay que subrayar que estos crímenes ponen en riesgo la biodiversidad, amenazando a esas especies, pero, por otro lado, producen cerca de US\$75 millones anuales, solo entre África y Asia.

Pero, no solamente esas especies están en la mira de los criminales. Según el Fórum Mundial de la Naturaleza, los traficantes comercializan por año, algo como 100 millones de toneladas de peces, 1,5 millón de pájaros y 440 mil toneladas de plantas medicinales. ${ }^{5}$

Los estudiosos e investigadores afirman que los grupos criminales utilizan las mismas rutas y "modus operandi" para el narcotráfico y se aprovechan de la falta de previsión en las leyes o en lo sistema penal de los países.

\footnotetext{
${ }^{4}$ Imágenes tomadas de la internet: https://www.google.es/search?q=IMAGENS+DE+TR\%C3\%81FICO+DE+MARFIM\&rlz=1C1NHXL ptBRBR711BR711\&source=Inms\&tbm=isch\&sa=X\&ved=0ahUKEwiYluKhpITTAhXB1RQKHSnDjQQ_AUICCgB\&biw $=1366 \&$ bih=613\#tbm=isch \&q=IMAGENS+DE+TR\%C3\%81FICO+DE+chifre+de+reinoceronte $*$, https://www.google.es/search?q=IMAGENS+DE+TR\%C3\%81FICO+DE+MARFIM\&rlz=1C1NHXL_ptBRBR711BR711\&source=Inms\&tbm=isch\&sa=X\&ved=0ahUKEwiYluKhpITTAhXB1RQKHSnDjQQ_AUICCgB\&biw $=1366 \& b i h=613 \#$ tbm=isch\&q=IMAGENS+DE+TR\%C3\%81FICO+DE+MARFIM+DE+ELEFANTE\&* e https://www.google.es/search?q=IMAGENS+DE+TR\%C3\%81FICO+DE+pele+de+tigre\&rlz=1C1NHXL ptBRBR711BR711\&source=Inms\&tbm=isch\&sa=X\&ved=0ahUKEwimya74poTTAhUE7RQKHdo DEgQ AUIBigB\&biw=1366\&bih=613.

${ }^{5}$ http://www.bbc.com/portuguese/noticias/2016/04/160331 atividades crime organizado fn
} 
Y esto se hace sentir de manera más preocupante en los países en desarrollo o con pocos recursos, donde los lucros exorbitantes y los pequeños riesgos apalancan el crecimiento de esa especial forma de criminalidad.
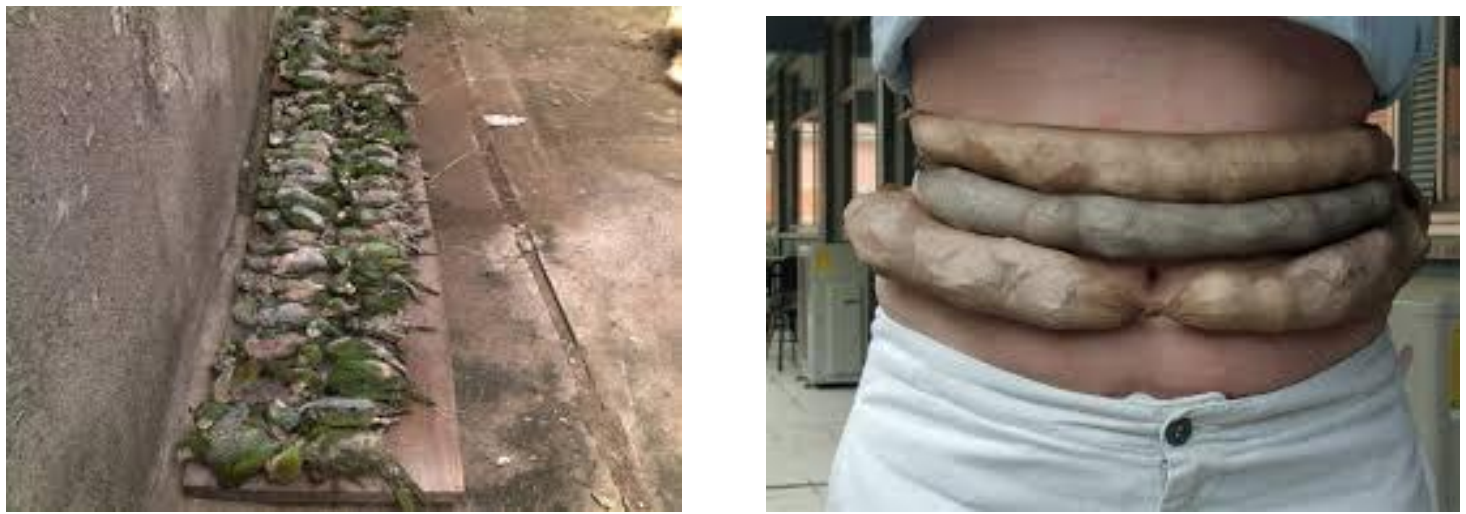

El tráfico de pájaros ${ }^{6}$ es muy importante en América del Sur y es responsable de la extinción en la naturaleza de la "ararinha azul"7, especie salvaje endémica de Brasil. Para tener una idea de los números con que se trafica en Brasil, sólo por la Policía Militar Ambiental de San Pablo, se incautan por año, entre 25.000 y 30.000 animales salvajes, la mayoría pájaros. ${ }^{8}$

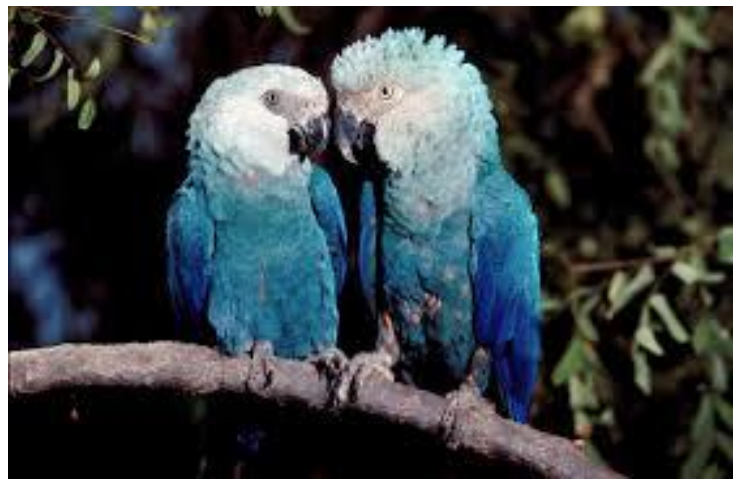

(Cyanopsitta spixii) ${ }^{9}$

\footnotetext{
${ }^{6}$ Imágenes tomadas de la internet: https://www.google.es/search?q=imagens+de+tr\%C3\%A1fico+de+aves\&rlz=1C1NHXL ptBRBR711BR711\&source=Inms\&tbm=isch\&sa=X\&ved=0ahUKEwj39quprYTTAhWDUBQKHUMVDmgQ AUICCgB\&biw=1366\&bih=613

${ }^{7}$ CAPARROZ, R.; MIYAKI, C.Y.; BAMPI, M.I.; WAJNTAL, A. (2001). «Analysis of the genetic variability in a sample of the remaining group of Spix's Macaw (Cyanopsitta spixii, Psittaciformes: Aves) by DNA fingerprinting». Biological Conservatiom. 99 (3): $307-$

311. doi: $10.1016 /$ S0006-3207(00)00196-8 - obra mencionada en https://pt.wikipedia.org/wiki/Ararinha-azul.

${ }^{8}$ https://www.amigosdanatureza.org.br/publicacoes/index.php/forum ambiental/article/viewFile/286/285

${ }^{9}$ https://es.pinterest.com/explore/ararinha-azul/
} 


\section{dA derecho ANIMAL la web center de los animales con derecho}

Con la finalidad de fortalecer la cooperación entre los representantes de los gobiernos de Colombia, Perú, Chile, Ecuador y Brasil en el combate al tráfico de especies salvajes, se realizó en Bogotá, Colombia, entre los días 14 y 17 de marzo de 2017, la "Conferencia Regional sobre Cooperación para Combatir el Tráfico de Especies Silvestres en Suramérica”, organizada por la Embajada de los EEUU.

Como se adelanta arriba, las organizaciones criminales amenazan la seguridad pública y nacional y los países no pueden hacer frente a ellas de forma aislada. Por lo tanto, conocer mejor la situación de cada país y cambiar las ideas para combatir el tráfico de animales silvestres, es una de las estrategias de los EEUU. Establecer redes regionales, trabajar con los gobiernos de forma organizada y cooperativa con otros sectores de la sociedad, es necesario para enfrentar esta forma especial de criminalidad.

Fueron 4 días de intenso trabajo, intercambio de informaciones y experiencias. Las presentaciones fueron hechas por los representantes de las policías, de las agencias aduaneras, de los órganos de control y fiscalización y de las fiscalías de los países invitados. De los EEUU hicieron presentaciones los presentantes del Consulado General, Embajada, Servicio de Peces y Fauna, Departamento de Interior, "Bureau of International Narcotics and Law Enforcement Affairs (INL)" y "United Nations Office on Drugs and Crime (UNODC)".

Al cabo de esos días, se proyectó la creación de un grupo regional para combatir tales crímenes, ya nombrado "SUDWEN - South America Wildlife Enforcement Network" y que recibe el apoyo de "Freeland Foundation", presentada por su Presidenta Ejecutiva en Brasil, Juliana Ferreira. 